\title{
Impact Propagation of Human Errors on Software Requirements Volatility
}

\author{
Zahra Askarinejadamiri \\ Dept of software engineering and information system \\ Faculty of computer science and information technology \\ Universiti Putra Malaysia \\ Serdang, Selangor, Malaysia
}

\author{
Abdul Azim Abd Ghani \\ Dept of software engineering and information system \\ Faculty of computer science and information technology \\ Universiti Putra Malaysia \\ Serdang, Selangor, Malaysia
}

\author{
Hazura Zulzallil \\ Dept of software engineering and information system \\ Faculty of computer science and information technology \\ Universiti Putra Malaysia \\ Serdang, Selangor, Malaysia

\section{Koh Tieng Wei} \\ Dept of software engineering and information system \\ Faculty of computer science and information technology \\ Universiti Putra Malaysia \\ Serdang, Selangor, Malaysia
}

\begin{abstract}
Requirements volatility (RV) is one of the key risk sources in software development and maintenance projects because of the frequent changes made to the software. Human faults and errors are major factors contributing to requirement change in software development projects. As such, predicting requirements volatility is a challenge to risk management in the software area. Previous studies only focused on certain aspects of the human error in this area. This study specifically identifies and analyses the impact of human errors on requirements gathering and requirements volatility. It proposes a model based on responses to a survey questionnaire administered to 215 participants who have experience in software requirement gathering. Exploratory factor analysis (EFA) and structural equation modelling (SEM) were used to analyse the correlation of human errors and requirement volatility. The results of the analysis confirm the correlation between human errors and $R V$. The results show that human actions have a higher impact on RV compared to human perception. The study provides insights into software management to understand socio-technical aspects of requirements volatility in order to control risk management. Human actions and perceptions respectively are a root cause contributing to human errors that lead to RV.
\end{abstract}

Keywords-Human factor; human errors; requirements volatility

\section{INTRODUCTION}

Software is developed based on the requirements of users which are obtained during the requirements gathering activity in the requirements engineering process in software development projects. The aim is to collect complete and unambiguous requirements. Nevertheless, not all projects are free from requirements changes or requirements volatility which involves additions, deletions, and modifications [1]. Frequent changes to requirements are a risk factor in software development projects [2].

Requirements engineering, which involves socio-technical aspects, is a critical and complex process. It has a vital role in reducing risks to a project and consequently increasing the success of software project $[3,4]$. Among the elements to achieve success in software projects are technology, processes, and methods but the use of them is based on judgment and the decisions of human [5]. Thus, human aspects are among the main challenges in requirements engineering.

A variety of research and studies have addressed the technical aspects of requirements gathering and requirements volatility. They show the impact of on productivity [6], software defects [1], and software release[7]. Moreover, not many studies focus on the factors that influence requirements volatility except that they are the communication between users and the developer and defined the methodology for requirements analysis and modelling [8]. A search on the ISI web of science shows that more than $70 \%$ of papers discuss the technical parts of software engineering and the software development process and less than $5 \%$ study the soft or human aspects of software development. Nevertheless, not many studies have focused on human factors as a vital component in controlling requirements volatility. Some researchers have explored human action and capability as reason of requirements volatility [9].

In this paper, we present a study on requirements volatility as a means to understand the impact of human errors on requirements gathering in requirements changes. It focuses on identifying and analysing human errors on requirements gathering which impact on requirements volatility. A model of human errors in relation to requirements volatility is proposed as a result of our extensive literature review. We employed quantitative approaches in validating the model. Thus, this study addresses the following research questions:

- Which human errors are relevant to requirements volatility in a software project?

- Which element of human errors has the most influence on requirements volatility?

Our results indicate the human errors which impact on software requirements changes are based on human action and goals, and human perceptions. 
This paper is organized as follows. Section II provides the related work on human errors and requirements engineering. The methodology employed in this study is described in Section III, followed by the results and discussion in Section IV. Section V is the conclusion of the study.

\section{RELATED WORK}

In the following section we derive and define the concept of human errors, human errors in RE and requirements volatility. We discuss around them to understand better relationship of human errors and requirements volatility.

\section{A. Human Errors}

The role of human is without doubt important to the successful development of software. For example, human reluctance to change may be important in controlling change in technically-based software processes or its tools [6]. However, in developing software we are often faced with development problems caused by human errors just like in other domain areas $[10,11]$. In general, human errors are defined as any human activity which leads to not achieving the goals of the system [12, 13]. In software engineering perspective, not achieving the goals of the system means there are failures caused by faults originated from human errors. Thus, human errors are the root of the failures in a software project. Despite the occurrences of the failures, understanding of the nature of the failure in relation to human errors is important. For instance after the occurrence of a crash between Boeing 747 at Tenerife Island airport and the nuclear power plant accident, there was a concern to understand the nature of these disasters [14].

Human errors can occur in any phases of the software development lifecycle (SDLC). However, in this study, we focus on software requirements errors which occur in the first phase of the SDLC. During this phase, issues such as imprecise information, and incomplete or loss of data [15] cause failures or delays in projects. As most of these activities are affected by persons, human errors should be addressed and analyzed as a means to rectify such errors.

According to Helander et al. [16], human errors are of two types namely, phenomenological, which is concerned with error consequence, and those causing the error. The first category focuses on how the error occurred while the second group focuses on why. Omissions and substitutions are examples of the first group while slips, mistake, and cognitive errors fall into the second classification. In another view, the level of planning and intention can also lead to the emergence of various errors [17]. If the plan for the project is well designed but the activities involved do not effectively implement it, a slip emerges. Nevertheless, there are also cases where the action adheres properly to the plan but the plan itself is flawed. In both cases, human behaviour has a significant role in the occurrence of errors.

Some studies focus on human behaviour as the root cause of human errors which should be analysed based on human behaviour. They mention that human behaviour is based on knowledge, skills, and rules. Rule-based mistakes rely on the wrong rules or procedures. Knowledge-based behaviour emerges when there are no rules or procedures in a new environment. Mistakes here occur in situations of incomplete or wrong knowledge or interpretations. Skill-based errors occur when the wrong intention results in inappropriate execution of the plan $[10,18]$. Overall, the occurrence of human errors is due to human behaviour which comprises rules, skills and knowledge.

A recent study on the assessment of human error on soft computing was conducted using fuzzy logic [19] which was used due to uncertainties in traditional human error risk assessments. Their model evaluated three risk factors in human error based on the fuzzy rule. Another study conducted a quantitative assessment of developer behaviour based on the data set [20]. They classified the behaviour of the developers in an automated way and applied statistical tools to analyse the model. In another work, software project human error reasons are classified into the attention of humans, communication error, and organization error (Harwood and Sanderson, 1986). The level of communication between stakeholders which is fully related to human personality is another issue in requirement engineering[21].

Apart from above, the psychological view of action slips are organized into 3 parts which are (a) errors in the formation of the intention (e.g., mode and description errors); (b) faulty activation of schemas (e.g., loss of intention and disordering of action components); and (c) faulty triggering (e.g., spoonerisms, blends, and intrusions of thoughts) [22]. According to human error theories, failure can happen in the goal, plan, and action stages of the human process [23]. Based on this idea, goals, and plans refer to something to be achieved and provide detailed steps for that purpose. The action is the implementation of the work to achieve a goal. Perception refers to the interpretation and evaluation of the action.

All the above mentioned studies focus on human errors in different dimensions. The following part focuses on studies on human error and requirement engineering which are at the root of many problems in requirements volatility.

\section{B. Human Errors in RE}

The various studies have been conducted identifying the relationship between human errors and requirements engineering. Lopes and Forster [23] focus on human error as one of the main reasons for RE failure. According to them, attention and memory error, communication error, organization errors, perception and interpretation errors, and violation are human errors that lead to RE failure. They presented a model for determining error types based on the type of problem although they also analyzed some aspects of human error. In addition, communication and interpretation errors have also been identified in requirements engineering and which are subject to user and developer communication in requirements gathering [24]. Usually, requirements elicited from customers are vague and incomplete and do not include adequate detailed information. Requirements are obtained through communication with stakeholders [25] and poor communication can reduce the quality of requirements gathering [26]. Undefined requirement process and misunderstanding are signs of poor communication in software requirements gathering [27]. 
Some techniques are presented for preventing defect in RE. In the paper titled "Preventing requirement defects: An experiment in process improvement", the authors categorized software requirement defects as error source (where the true requirement has been 'lost'); quality factor (functionality, usability, performance, etc.); related interface (user interface, third-party software, etc.); cost of handling and repair. Human and developer errors in this study are also considered as a source of defect in RE. Based on this study some techniques were presented which, if applied, can reduce failure of the project [28].

Scholars believe that human errors during the communication phase have a vital role to play in enhancing RE quality. They conducted their research using case studies. They classified communication and domain knowledge as two essential factors that impact on RE quality [29]. Simple omissions in communication can cause many challenges in requirements gathering [30]. In a similar study, researchers noted that trust relationship, increased knowledge, and better understanding are main elements that impact on the communication between users and developers. In one study, individual actors based on cognitive perspective, organizational factors, human flexibility, and human artfulness are the main contributors to human error that result in RE failure [31], while another study attributes it to organizational safety and human behaviour [32]. These factors are some aspects of human behaviour which cause human errors in the system.

In requirements engineering, verification and validation are important steps for development of the product as discussed in the paper titled "Challenges and practices in aligning requirements with verification and validation: a case study of six companies" [33]. The authors believe that weak communication is an example of weak RE that can cause many problems in software project such as invalid requirements, software quality problem, and wasted effort. Weak communication occurs through human errors, and the paper stressed the importance of human communication in requirement gathering in ensuring the success of a project.

Some studies have focused on the human personality and attitude on software engineering and apply theories such as Myers-Briggs Type Indicator (MBTI), the Big Five Personality Theory, and so on [5] [34][35].

All the above-mentioned studies focus on human errors and its metrics in requirements engineering while this research highlights requirements volatility in SDLC. Many scholars believe that requirements volatility is the root cause of project failure [1][8][36][37]. Due to the lack of studies on human errors and requirements volatility, this research focuses on this area especially in regard to the requirements gathering phase. Therefore, researchers try to list the human errors which impact on requirement changes based on the requirements engineering aspect. Scholars believe that requirements volatility is a metric of RE [8][38]. This study examines the human errors which impact on RV based on a review of RE papers.

\section{Requirements Volatility}

Based on the literature, requirements volatility is described as the following factors:

- Requirement instability: defined as requirements that fluctuate between the earlier and later stages, and differ at the start and end of the project [8][37][39].

- Requirement diversity: refers to the difficulty among shareholders in reaching agreement on the requirements and in customizing the software to one set of users requiring much effort to be expended in incorporating the requirements of the various users [8][37].

- Project Size: refers to the number of requirement changes including additions, modifications, and deletions in a software project [40]. Total development effort, project cost, and number of user representatives are involved [8][36].

\section{METHODOLOGY}

This section defines how the hypotheses were formed and validated, and describes the methodology and processes used to achieve the objectives of the research. The main research questions of this study are as follows:

$>$ Which human errors are relevant to requirements volatility in a software project?

Which element of human errors has the most influence on requirements volatility?

The first step in conducting the research based on the research questions is selecting research approach. It is a plan of research that determines the method of data collection and assumption validation, analysis, and interpretation [41].

\section{A. Conceptual Framework}

In order to present the hypotheses, researchers reviewed the papers to collect data for forming the model. By reviewing human errors on requirement engineering, we can collect human errors on requirement volatility. 
TABLE I. CONSTRUCt AND ITEMS OF PRESENTED Model

\begin{tabular}{|l|l|l|}
\hline construct & Items & Description \\
\hline \multirow{4}{*}{$\begin{array}{l}\text { human action } \\
\text { and goal }\end{array}$} & $\mathrm{A} 1$ & Substitution of word or alphabet \\
\cline { 2 - 3 } & $\mathrm{A} 2$ & Omitting word or sound \\
\cline { 2 - 3 } & $\mathrm{A} 3$ & Gap in attention and memory failure \\
\cline { 2 - 3 } & $\mathrm{A} 4$ & Omitting particular activity \\
\cline { 2 - 3 } perception & $\mathrm{A} 5$ & Using or disregarding particular activity \\
\cline { 2 - 3 } & $\mathrm{A} 6$ & Emotional makeup \\
\cline { 2 - 3 } & $\mathrm{A} 7$ & Failure to set an objective \\
\hline \multirow{5}{*}{$\begin{array}{l}\text { Requirements } \\
\text { volatility }\end{array}$} & $\mathrm{P} 1$ & $\begin{array}{l}\text { Requirement gatherers' perception and } \\
\text { interpretation }\end{array}$ \\
\cline { 2 - 3 } & $\mathrm{P} 2$ & Cognitive behaviour \\
\cline { 2 - 3 } & $\mathrm{P} 3$ & Understanding of requirement \\
\cline { 2 - 3 } & $\mathrm{RV} 1$ & Requirement fluctuate in earlier stage \\
\cline { 2 - 3 } & $\mathrm{RV} 2$ & Requirement fluctuate in later stage \\
\cline { 2 - 3 } & $\mathrm{RV} 3$ & $\begin{array}{l}\text { Different in the requirement of start and final } \\
\text { in the project }\end{array}$ \\
\cline { 2 - 3 } & $\mathrm{RV} 4$ & $\begin{array}{l}\text { Difficulty for stockholders to reach agreement } \\
\text { on requirements }\end{array}$ \\
\cline { 2 - 3 } & $\mathrm{RV} 5$ & $\begin{array}{l}\text { Difficulty to customize the software to one set } \\
\text { of users }\end{array}$ \\
\cline { 2 - 3 } & $\mathrm{RV} 6$ & $\begin{array}{l}\text { A lot of effort had to be spent in incorporating } \\
\text { the requirement of the various user }\end{array}$ \\
\cline { 2 - 3 } & $\mathrm{RV} 7$ & $\begin{array}{l}\text { Number of requirement change include add, } \\
\text { modified and delete in a software project }\end{array}$ \\
\cline { 2 - 3 } & RV8 & $\begin{array}{l}\text { Total development effort, project cost and } \\
\text { number of user representatives involved }\end{array}$ \\
\hline
\end{tabular}

Thus, the selected human errors for this research are described in two categories as follows:

- Goal and Action: is defined as requirements gathering for software development to be achieved by the requirement gatherer based on his plan and action. The human errors in this case are failure to set an objective, substitution of word or alphabet, omitting word or sound, gaps in attention and memory failure, omitting a particular activity, and using or disregarding a particular activity.

- Perception: relates to the act of perceiving, interpreting, and evaluating the results of the requirement gathering action. The activities in this type of human error are requirement gatherers' perception and interpretation, cognitive behaviour, and understanding of requirements.

Although ideally the requirements for software projects should be complete and unambiguous before the design phase, in real-life situations changes to them are unavoidable. Requirements volatility leads to redesigning, recoding, and retesting and may even result in the failure of the project [42]. There is a direct relationship between requirements volatility and defect density [1]. Understanding human errors is a key element for managing requirements volatility in order to achieve success in a software project.

Therefore, the relationships were analysed based on the above mentioned elements on requirements volatility and human errors. In this study, RV is considered a dependent variable and human errors as independent variables.

To control RV, it is necessary to manage or minimize human error. Based on the literature reviews, human errors are considered as significant elements in this research. Human errors are classified as human actions, goals, and perceptions.

The hypothesized model of this paper is presented in Fig 1. It shows the correlation between human errors and requirement volatility. Also all constructs of the presented model is described in Table I.

\begin{tabular}{|c|c|}
$\begin{array}{c}\text { Independent } \\
\text { variable }\end{array}$ & $\begin{array}{c}\text { Dependent } \\
\text { variable }\end{array}$ \\
\hline $\begin{array}{c}\text { Human } \\
\text { errors }\end{array}$ & $\begin{array}{c}\text { Requirements } \\
\text { volatility }\end{array}$ \\
\hline
\end{tabular}

Fig. 1. Hypothesized model of this study

\section{B. Phase2: Model Evaluation}

Following the presentation of the model a quantitative approach was done to test and validate it using data that was collected and analysed. One of the main aims of quantitative research is to understand the relationship between variables [43]. This research is conducted based on the Structural Equation Modelling (SEM) technique with the aim of achieving a convergence of opinions concerning human errors and requirement volatility from persons who have experience in software requirement gathering. Due to the lack of theories in this research, this study is exploratory and a questionnaire was administered among participants to gather data for analysing human errors and software requirement volatility.

\section{Participants}

A sample population of software requirements gatherers should preferably be chosen as representatives in this study. Unfortunately, there is no data available for such a population. As this study also faced financial and time constraints in selecting a sample, persons with experience in software requirements gathering were selected as respondents.

\section{Sample Size}

Sample size has a significant role in statistical analysis and in this study it is based on the statistical analysis technique that will be used for the research. In this research SEM and SPSS is used for data analysis. There is no consensus on the exact sample size for SEM and researchers have different ideas on that. SEM needs an appropriate sample size in order for the estimation to be reliable and valid. Some scholars mention that a sample size of 200 is a critical number for analysing structural equation modelling [44][ 45] while Kline [46] suggests a number between 200 to 400 . In general a minimum sample size of 200 is appropriate. This study involved 215 respondents.

\section{E. Data Collection}

This section describes the procedure for the validation hypothesises of this research. In order to examine them, the survey approach was done. The analyses of human errors on requirement volatility are based on responses to the questionnaire which were distributed online and by hand. Online questionnaire in google doc and kwicksurvey were developed to facilitate respondents. The online questionnaires shared in the social media were those related to requirement 
engineering and software engineering as shown in Table II. Apart from online data collection, due to the accessibility of researchers in Iran and Malaysia, the questionnaires were distributed in Technology Park Malaysia and Cyberjaya where most Malaysian software companies are located.

The questionnaire was designed in order to understand the relationship between requirements volatility and human errors. It was based on the literature reviews in order to provide the aims of this research. A 5-point Likert scale with a range of strongly disagrees to strongly agree was used.

\section{TABLE II. ONLINE QUESTIONNAIRE SHARED IN SOCIAL MEDIA}

\begin{tabular}{|l|l|}
\hline $\begin{array}{l}\text { Social } \\
\text { media }\end{array}$ & Group \\
\hline & $\begin{array}{l}\text { Requirement engineering, requirement } \\
\text { engineering specialist group } \\
\text { (RESG),Requirement management and analysis, } \\
\text { Mobile_software_developer, Mobile software } \\
\text { development, Software developer engineer in } \\
\text { Test (SDET), Software designer and } \\
\text { development, Software development } \\
\text { management professional, Swedish association } \\
\text { group requirement engineering(SARE), software } \\
\text { developer, software and technology, IT and } \\
\text { software project management, computer and } \\
\text { software engineering professionals groups }\end{array}$ \\
\hline $\begin{array}{l}\text { Facebook } \\
\text { group }\end{array}$ & $\begin{array}{l}\text { Software engineer, I am a software engineer, } \\
\text { Software engineering, Software developer }\end{array}$ \\
\hline $\begin{array}{l}\text { Yahoo } \\
\text { group }\end{array}$ & $\begin{array}{l}\text { Developers_for_ever, Leandevelopment, } \\
\text { Requirement-engineering }\end{array}$ \\
\hline
\end{tabular}

\section{F. Data Analysis}

SPSS version 21 was used for the statistical analysis. This study addressed treatment of the missing data, tested for normality of data, and identified outlier by using SPSS. An analysis was also made of the demographic profiles of respondents for the study. Additionally, Exploratory Factor Analysis (EFA) was done by SPSS to summarize the variable in a different group and analyse the information. It classified the factors of the research model based on principal component analysis (PCA) by the Varimax rotation method. EFA was employed based on common factor model to summarize variables for factors [47]. In addition, the reliability of the construct and model was checked by Cronbach alpha test with a value greater than 0.7 applied to confirm the reliability of the model.

SEM is an accumulation of statistical methods that look for clarifying connections among different variables. It empowers analysts to look at the interrelationships among different dependent and independent variables [47]. The basis for selecting SEM for investigation in this research is its capacity to test relationships of complicated models having multivariate variables. Further, it offers excellent statistical procedures for managing complex models [47] as well as flexibility in statistical tests for the measurement of invariance [48]. Confirmatory Factor Analysis (CFA) allows for the analysis of relationships between dependent and independent variables (measurement model) [49]. SEM consists of two step which are measurement modelling and structural modelling. In order to perform SEM, CFA test will be done. It identifies the relationship between constructs and indicators which will be done by CFA using the AMOS software.
In order to do measurement modelling evaluation, Confirmatory Factor Analysis (CFA) in AMOS was used to examine the relationship between variables and relationships between the constructs and indicators. Model checking based on goodness of fit was conducted and the hypothesised model was improved the fit. This research used structural modelling to test the interrelationship between dependent and independent variables hypothesized in this research. Structural modelling was done to test the correlation between human error and requirements volatility and how human errors impact on RV.

\section{RESUlt AND DISCUSSION}

The majority of respondents in this study were male and had more than 5 years of work experience in software development projects. In this sample, we addressed a variety of respondents from different organizations, countries, and positions. The demographic details of respondents are shown in Table III.

This section discusses construct validity and reliability and presents the results of the exploratory factor analysis (EFA) and the structural equation modelling (SEM). First, the EFA tests are used to identify the relationship between measured variables. After identifying the relationship, the model fit was tested by CFA. In order to conduct EFA and CFA tests, the data should be normal with no missing data and outliers. Data screening were done to check for missing data, normality and outlier. In this study there were six missing values which were replaced by using the median technique which is a good means to address low levels of missing data. Also, normality of data was checked by analysing Skewness and Kurtosis and the results show they were between -2 and +2 which shows normality of data. Outliers are defines as an observation that are distinctively different from other values [47], and problematic ones should be identified in research. The two main outliers are univariate and multivariate outliers with the former referring to data consisting of extreme values on variables while the latter is a combination of unusual values [46]. Also, identifying outliers will be discussed in the section on SEM prior to conducting the CFA.

TABLE III. DEMOGRAPHIC DETAILS OF RESPONDENTS ( $(\mathrm{N}=215)$

\begin{tabular}{|l|l|l|l|}
\hline Variable & Category & frequency & $\%$ \\
\hline \multirow{3}{*}{ Gender } & Male & 130 & 61 \\
& Female & 82 & 38.5 \\
& Others & 3 & 0.5 \\
\hline \multirow{5}{*}{ Age } & $21-30$ & 92 & 42.8 \\
& $31-40$ & 100 & 46.5 \\
& Over40 & 23 & 10.7 \\
\hline \multirow{5}{*}{ Job title } & Software developer & 76 & 35.3 \\
& Software engineer & 59 & 27.4 \\
& System analysts & 9 & 4.2 \\
& Function analyst & 5 & 2.3 \\
& Business Analyst & 13 & 6.0 \\
& Information architect & 3 & 1.4 \\
& Others & 50 & 23.3 \\
\hline \multirow{2}{*}{ Type of } & Governmental & 2 & .9 \\
organization & Semi-governmental & 8 & 3.7 \\
& Private & 205 & 95.3 \\
\hline \multirow{2}{*}{ Work } & Less than 5 years & 74 & 34.4 \\
Experience & 5-10 years & 94 & 43.8 \\
& More than 10 years & 45 & 20.9 \\
\hline
\end{tabular}




\section{A. Construct validity and reliability}

Based on above criteria, the results show that Human Action and Goal and Human Perception and RV are valid constructs. The construct validity of the instrument used in the research has been assessed through convergent validity and discriminant validity. Convergent validity alludes to examining whether the degree of relationship between two measures of construct in theory is valid in fact. Average variance extracted (AVE) and construct reliability (CR) were used to calculate convergent validity. In order to assess convergent validity, the cut-off AVE point should be greater than 0.5 and CR should be greater than AVE. The results of this study are shown in Table IV indicating that the value of CR and AVE are more than the cut-off point. Discriminant Validity refers to whether a construct is truly distinct from others. It is assessed using Maximum Shared Value (MSV), AVE, and Average Shared Square Variance (ASV). MSV should be less than AVE and ASV should be less than AVE to establish that the construct's discriminant validity is an accepted criteria [47].

TABLE IV. RESUlt of MEASUREMENT MODEL VALIDITY

\begin{tabular}{|l|l|l|l|l|}
\hline & CR & AVE & MSV & ASV \\
\hline Action & 0.886 & 0.526 & 0.504 & 0.291 \\
\hline perception & 0.784 & 0.548 & 0.504 & 0.252 \\
\hline $\begin{array}{l}\text { Requirement } \\
\text { volatility }\end{array}$ & 0.895 & 0.517 & .0784 & 0.039 \\
\hline
\end{tabular}

Based on results in Table IV, it can be said that the values support discriminant validity. Reliability is another important issue which should be tested. For this test, this study employed SPSS to provide the Cronbach alpha. The results show the alpha $=.884$ for 18 items of this study which is greater than the cut-off point and shows that the hypothesized model is reliable.

\section{B. Exploratory factor analysis (EFA)}

Before conducting EFA, the outliers should be identified. In this study, there was no univariate outlier, because the Likert Scale was used for responses and participant cannot respond beyond this 5 -scale range. In order to identify the multivariate outlier Mahalanobis distance $\left(\mathrm{D}^{2}\right)$ test was used to measure the distance between each observation and compared to the mean of the observations [50]. However, the results show that there were a few outliers in this study. Hair et al. [47] mention that the removal of outliers can improve the multivariate analysis but has the risk of decreasing generalizability. Also they believe that in a sample size greater than 100, if $\mathrm{MD}^{2} / 2 *$ number of items measures do not exceed 3 or 4 , the cases remain in the data and are not considered as an outlier.[47] In this study the levels for the $\mathrm{MD}^{2} / 2$ *number of items of suspected outliers are less than 3 which do not exceed a critical value. Thus, in this research there was no evidence of multivariate outlier and all data remains in the research.

EFA is a statistical method for identifying the structure of relative variables through extraction and rotation. Extraction is used to determine the factors of the variables while rotation is used to provide a pattern for better interpretation [47]. To conduct the EFA for this study, principal components analysis (PCA) was used for the extraction and Varimax rotation was performed for the rotation by SPSS. Table V shows the results of KMO and Bartlett's. The KMO value is used to measure sample adequacy and suitability of data for construction which in this research is 0.914 indicating that the number of data for analysis is acceptable and suitable. Communality is a criterion of the EFA which is extracted using PCA and shows the common factor analysis. The extraction values in the communality table VI indicate the proportion of each variable's variance that can be explained by the principal components. Items with higher values are well represented in the common factor space while variables with low values are not. In this study the communalities of items vary from .557 to .682 . The lowest communality value is the Failure to set an appropriate objective.

TABLE V. KMO AND BARTLETT'S TEST

\begin{tabular}{|ll|l|}
\hline \multicolumn{2}{|l|}{ Kaiser-Meyer-Olkin Measure of Sampling Adequacy. } & .910 \\
& Approx. Chi-Square & 1808.68 \\
Bartlett's Test of & Df & 153 \\
Sphericity & Sig. & .000 \\
\hline
\end{tabular}

One of the important questions in this study is identifying the factors based on items and this was done using principal component analysis. Table XII is extracted based on Eigen values greater than one. Variances of $25.81 \%, 23.28 \%$, and $11.909 \%$ are explained by the first, second, and third factors respectively while the remaining variance is explained by the other four factors. In order to achieve a clear pattern of loading, rotational strategies were conducted to identify the factors. Varimax rotation was selected for this study to maximize the variance on the new axes. The factors were extracted using the Rotated Component Matrix. By performing EFA, the number of constructs and indicators were extracted. Table VII shows the results of constructs and indicators. It can be said that the results confirm the existence of the three factors based on the selected items. Based on these results, the correlations of items were extracted and three constructs of this study namely, Goal and Action, Perception, and Requirement Volatility were identified.

TABLE VI. COMMUNALITY OF ITEMS

\begin{tabular}{|l|l|}
\hline Items & Extraction \\
\hline Substitution of word & .652 \\
Omitting Word & .580 \\
Gap in attention & .578 \\
Omitting activity & .554 \\
Disregarding particular rule & .626 \\
Emotional make up & .683 \\
Failure to set appropriate objective & .560 \\
Perception and interpretation & .714 \\
Cognitive behaviour & .679 \\
Understanding of requirement & .658 \\
Requirement Fluctuated in earlier & .570 \\
stage & \\
Requirement fluctuated in later & .597 \\
stage & .589 \\
Different requirement identified & \\
Difficult stockholders to reach & .631 \\
agreement & .594 \\
Effort had to be spent in & .561 \\
incorporating & \\
Difficult to customize software & .555 \\
Number of requirement change & \\
Total development effort & \\
\hline
\end{tabular}


TABLE VII. ROTATED COMPONENT MATRIX

\begin{tabular}{|l|l|l|l|}
\hline & \multicolumn{3}{|l|}{ Component } \\
\cline { 2 - 4 } & 1 & 2 & 3 \\
\hline Difficult stakeholders to reach & .791 & & \\
agreement & .773 & & \\
Total development effort & .759 & & \\
Requirement fluctuated in later stage & .757 & & \\
Different requirement identified & .749 & & \\
Requirement Fluctuated in earlier stage & .735 & & \\
Effort had to be spent in incorporating & .732 & & \\
Difficult to customize software & .727 & & \\
Number of requirement change & & .806 & \\
Disregarding particular rule & & .781 & \\
Emotional make up & & .743 & \\
Substitution of word & & .716 & \\
Omitting Word & & .711 & \\
Failure to set appropriate objective & & .710 & \\
Gap in attention & & .661 & \\
Omitting activity & & & .784 \\
Perception and interpretation & & & .766 \\
Understanding of requiremnt & & & .737 \\
Cognitive behaviour &
\end{tabular}

One of the important questions in this study is on identifying the factors based on items. Principal component analysis was conducted to extract the factors.

Based on Eigen values greater than one Table VII is extracted. Variances of $25.81 \%, 23.17 \%$, and $11.80 \%$ are explained by the first, second, and third factors, respectively while the remaining variance is explained by the other four factors.

\section{Structural Equation Modeling (SEM)}

In SEM, there are three basic types of model fit indices namely, absolute, incremental, and parsimonious [51]. Their criteria are presented in Table XIII. In this research, three factors were considered in the measurement model, which are Human Action and Plan (A), Human Perception (P), and Requirement Volatility (RV). These factors are measured by using ten items. The measurement model of this research is evaluated by testing the maximum likelihood (ML) as provided by AMOS. The initial results of CFA in this research are shown in Table XIII. The chi-square statistics $(\chi 2=156.881, \mathrm{df}=1.188)$ was significant at $\mathrm{p}<0.05$ and reveal that the fit of data to this measurement model should be accepted. It shows that the presented model, $95 \%$ can generalize to real model. Due to the sensitivity of the chisquare statistic to the sample size and its normality it is not appropriate to rely only on this item. Therefore, other fit indices such as AGFI, CFI, RMR, RMSEA, PCLOSE, PCFI, and IFI are used to assess the measurement model. In order to reflect model fit, Jaccard and Wan [52] recommend reporting at least three fit tests comprising one absolute, one relative, and one parsimonious. The results of these criteria are presented in Table XIII.

The results of this study show that the value of RMR $=0.018, \quad$ CFI $=0.989, \quad$ RMSEA $=0.026, \quad I F I=0.989$, AGFI $=0.911, \mathrm{PCFI}=0.853$, and Pclose $=1$ and indicate that the value of the model fit is above the cut-off point and it can be said that the model is fit. We can refine the model in order to achieve a better model fit [46] and some techniques are presented for that purpose. The standardize loading factor should be greater than 0.5 to be acceptable in model [53]. Additionally, a standard residual value between 2.58 and -2.58 is acceptable [47]. An assessment of the results shows that the values of the standard residual and loading factors are above the cut-off point value and are acceptable. It can say that the model is fit. Thus the Final measurement model is presented in fig 2 .

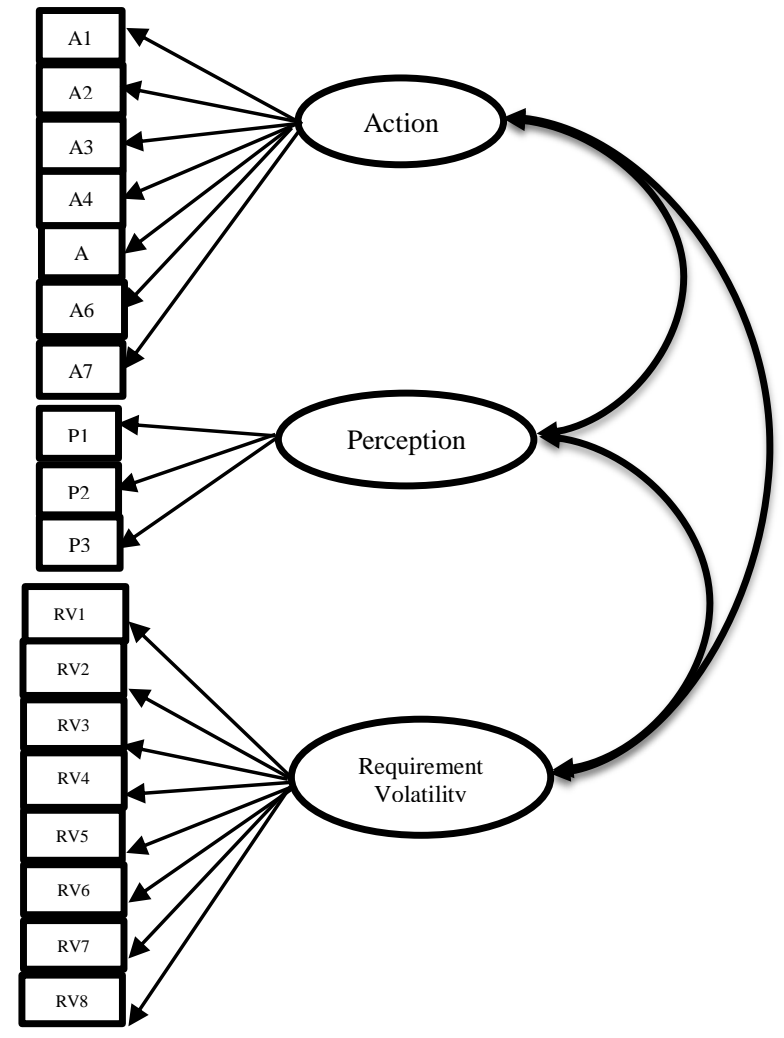

Fig. 2. Final Measurement Model

\section{Structural Model Evaluation and Hypotheses Testing}

This part discusses hypotheses testing. The two hypotheses of presented model in this research are presented in Table VIII. According to $\mathrm{H} 1$, there is a positive relationship between human goal and action and Requirement Volatility. Similarly, $\mathrm{H} 2$ indicates the positive correlation between human perception and requirement volatility. This section tests the relationship between these independent variables with requirement volatility. The final model was drawn by AMOS (Fig 3).

TABLE VIII. Structural Model Evaluation AND Hypotheses TESTING

\begin{tabular}{|l|l|l|l|}
\hline Construct & code & hypothesise & $\begin{array}{l}\text { Hypothesised } \\
\text { Relationships(positi } \\
\text { ve/negative) }\end{array}$ \\
\hline Human Action & A & H1 & A $\rightarrow$ RV \\
\hline Human perception & P & H2 & P $\rightarrow$ RV \\
\hline
\end{tabular}




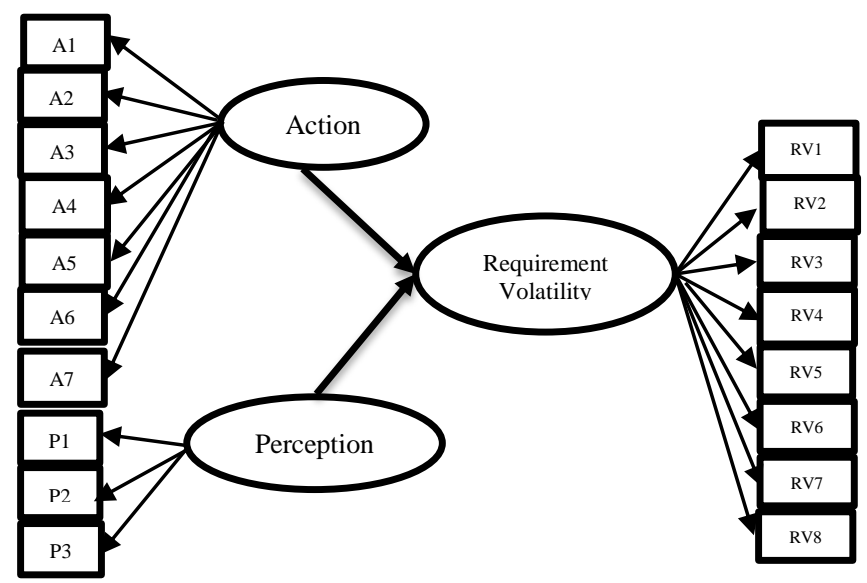

Fig. 3. Structural Model

A coefficient parameter assessment should be done for evaluating this model. This model has two latent constructs which are defined by ten items. In order to evaluate the model, factor covariance which is the critical ratio will be checked to be greater than 1.96 for an estimate. In this case, it can be said that the factor covariance is significant. Consequently the coefficient value is less than 0.05 and is statistically significant [47]. The critical ratio is calculated by dividing the regression weight (estimate) by the standard error (SE). The results of the coefficient parameter assessment for the two factors are presented in Table IX. As shown, the assessment for human action and perception was at the significant level $\mathrm{p} \leq .05$. Additionally standardize regression weight of human action and goal, and human perception estimated 0.51 and 0.27 which indicate that human errors based on action and goal have a $51 \%$ impact on RV compared to $27 \%$ for the impact of perception.

TABLE IX. REGRESSION WEIGHT

\begin{tabular}{|lll|llll|}
\hline & & & Estimate & S.E. & C.R. & P \\
\hline RV & $<---$ & A & 0.51 & .13 & 3.934 & .001 \\
RV & $<---$ & P & -0.27 & .074 & -3.677 & $* * *^{1}$ \\
\hline
\end{tabular}

TABLE X. HYPOTHESIS TESTING

\begin{tabular}{|l|l|l|l|l|}
\hline Construct & $\begin{array}{l}\text { cod } \\
\text { e }\end{array}$ & hypothesise & $\begin{array}{l}\text { Hypothesised } \\
\text { Relationships(posit } \\
\text { ive/negative) }\end{array}$ & $\begin{array}{l}\text { Sup } \\
\text { port } \\
\text { ed }\end{array}$ \\
\hline $\begin{array}{l}\text { Human } \\
\text { Action }\end{array}$ & $\mathrm{A}$ & $\mathrm{H} 1$ & $\mathrm{~A} \rightarrow \mathrm{RV}$ & Yes \\
\hline $\begin{array}{l}\text { Human } \\
\text { perception }\end{array}$ & $\mathrm{P}$ & $\mathrm{H} 2$ & $\mathrm{P} \rightarrow \mathrm{RV}$ & Yes \\
\hline
\end{tabular}

The results of the tests reveal that hypotheses H1was positive and $\mathrm{H} 2$ was negatively statistically significant. The results suggest that standardized estimates for these hypotheses ( $\beta=0.51,0.27$, respectively) indicate statistical significance and thus show support for these hypotheses. These results show the statistically significant connection between human errors and requirements volatility. People with higher human error can increase the requirements volatility and it is similar with the findings reported in studies such as Lopes et al. [23], Decker [27], and Andrew and Brad [54].

\footnotetext{
${ }^{1}$ Less than 0.001
}

In addition to this general finding, a more detailed analysis of the results of this study indicated the following. Table XI shows the Standardized Regression Weights of the indicators of IV constructs. Based on these results, it can be stated that A1 (Substitution of word or alphabet) and A6 (Emotional makeup) have the most influence on the goal and action constructs of human errors and consequently on RV. In contrast, A7 (Failure to set an objective) has less impact on goal and action constructs of human errors and consequently on RV. The results show that the root of RV are based on human errors are goal and action of human at work. Thus, it is necessary to decrease RV by controlling human goal and action. This is significant information for software manager to improve their requirement gatherer skill in goal and action skill of them for requirements gathering to decrease human errors and consequently requirements volatility. In the human errors perception construct, P1 (Requirement gatherers' perception and interpretation) and P3 (Understanding of requirements) respectively have the highest and lowest impacts on this construct and on RV subsequently.

TABLE XI. STANDARDIZED REGRESSION WEIGHTS OF INDICATORS OF IV CONSTRUCTS

\begin{tabular}{|l|l|}
\hline Indicators--->construct & Estimate \\
\hline A1--->A & .778 \\
\hline A2--->A & .721 \\
\hline A3--->A & .720 \\
\hline A4--->A & .709 \\
\hline A5--->A & .702 \\
\hline A6--->A & .785 \\
\hline A7--->A & .660 \\
\hline P1--->P & .736 \\
\hline P2--->P & .709 \\
\hline P3--->P & .687 \\
\hline
\end{tabular}

\section{E. Implication for SE practice and research}

Based on theoretical implication, this study proposes a model in the context of human errors in software development. This study answers the call to examine the causes of RV in requirements gathering. The findings suggest that human errors impact on RV in the requirements gathering. This research has provided extended knowledge in the domain of $\mathrm{RV}$ from a developers' perspective. Additionally, this research attempts to reduce the paucity of research on the role of human errors on RV. Unfortunately, very little study is known about the human errors on RV in software requirements gathering. Another significant contribution of this study is the instrument used for collecting the research data. There is a dearth of instruments for measuring RV and human errors constructs. This instrument or questionnaire has been carefully designed, developed, and statistically validated and thus can be used for future research particularly in the area of RV and human error. Previous researches have focused on the technical causes of RV while this study highlights the socio-technical aspects. In short, in investigating the root causes of RV this study has focused on human errors, especially in communication for requirements gathering.

Findings of this research study have practical implication for managers of software companies. First, in order to control requirements volatility in software development activities, project managers must have a good understanding of how to 
facilitate and cultivate effective communication between requirements gatherers and users. Emphasis should be given into identifying and understanding the enablers and impediments towards communication for software requirements gathering. From our findings, serious consideration in the areas of human errors must be taken in order to manage the communication errors issues. Further, the emphasis given will assist project managers or team leaders improve the capability and behaviour of requirements gatherers in communication during the software requirements gathering stage. We believe that our effort fills the gap due to lack of understanding and prescription on the socio-technical aspects of RV in software development. We propose a model of human errors on RV that shows key human errors that have the potential in stimulating $\mathrm{RV}$, and directly impacting on the quality of gathered requirements. In addition, this study signifies that human errors were identified as the elements that impact on RV with human action and goal having the most impact on it while human perception are other human errors which impact on RV. Hence, software managers should consider the human errors of the requirements gatherer as a means to manage and achieve better RV.

\section{FUTURE WORK}

This paper developed an integrated human errors model that provides a systematic way to understand RV due to human factors comprising human action and human perception. Several beneficial areas for future research, however, remain to be explored. For example, the results of current research are limited to RV and future research may apply or replicate this study in other software development domains. Also, there are some other human factors that impact on RV and could be apply to this model as future work.

\section{CONCLUSION}

This work provides the position of human errors to the processes of RE and, consequently, RV in order to improve them by minimizing errors. Thus, first of all, the importance of different causes of human error in software requirements gathering was collected based on qualitative research. Then these hypotheses and models were validated by analysing the collected response of participants. By identifying the different root causes of human errors, we confirmed that they have an impact on requirements volatility in software requirements gathering. Software managers are frequently confronted with the risk of requirements changes which give rise to many issues in their maintenance management operations. Knowing the roots of this challenge enables them to be controlled more effectively. In short, some human errors based on the constructs of goal and action and perception which impact on RV were presented. The result shows that goal and action of humans has a higher impact on RV compared to their perceptions.

\section{REFERENCES}

[1] Y. K. Malaiya and J. Denton, "Requirements volatility and defect density," in Software Reliability Engineering, 1999. Proceedings. 10th International Symposium on, 1999, pp. 285-294.

[2] Q. Wang, D. Pfahl, and D. Raffo, "Making Globally Distributed Software Development a Success Story," in International Conference on Software Process, ICSP 2008, Leipzig, Germany, May 10-11, 2008.
[3] N. Juristo, A. M. Moreno, and A. Silva, "Is the European industry moving toward solving requirements engineering problems?," IEEE software, vol. 19, pp. 70-77, 2002.

[4] D. Mishra, A. Mishra, and A. Yazici, "Successful requirement elicitation by combining requirement engineering techniques," in Applications of Digital Information and Web Technologies, 2008. ICADIWT 2008. First International Conference on the, 2008, pp. 258-263.

[5] R. Feldt, L. Angelis, R. Torkar, and M. Samuelsson, "Links between the personalities, views and attitudes of software engineers," Information and Software Technology, vol. 52, pp. 611-624, 2010.

[6] M. Lane and A. Cavaye, "Management of Requirements Volatility Enhances Software Development Productivity," in Australian Conference on Requirements Engineering (ACRE), Geelong, Australia, 1998.

[7] G. Stark, A. Skillicorn, and R. Ameele, "An examination of the effects of requirements changes on software releases," CROSSTALK The Journal of Defence Software Engineering, pp. 11-16, 1998.

[8] D. Zowghi and N. Nurmuliani, "A study of the impact of requirements volatility on software project performance," in Software Engineering Conference, 2002. Ninth Asia-Pacific, 2002, pp. 3-11.

[9] N. Ibrahim, W. M. W. Kadir, and S. Deris, "Propagating Requirement Change into Software High Level Designs towards Resilient Software Evolution," in 2009 16th Asia-Pacific Software Engineering Conference, 2009, pp. 347-354.

[10] D. A. Norman, The design of everyday things: Revised and expanded edition: Basic books, 2013.

[11] J. Rasmussen, "Human errors. A taxonomy for describing human malfunction in industrial installations," Journal of occupational accidents, vol. 4, pp. 311-333, 1982.

[12] G. S. Walia and J. C. Carver, "A systematic literature review to identify and classify software requirement errors," Information and Software Technology, vol. 51, pp. 1087-1109, 2009.

[13] J. Senders and N. Moray, "Human error," Cause, prediction and reduction, Orono, Univ. Maine, 1991.

[14] J. Reason, Human error: Cambridge university press, 1990.

[15] D. Firesmith, "Common Requirements Problems, Their Negative Consequences, and the Industry Best Practices to Help Solve Them," Journal of Object Technology, vol. 6, pp. 17-33, 2007.

[16] M. G. Helander, T. K. Landauer, and P. V. Prabhu, Handbook of human-computer interaction: Elsevier, 1997.

[17] K. Harwood and P. Sanderson, "Skills, rules and knowledge: A discussion of Rasmussen's classification," in Proceedings of the Human Factors and Ergonomics Society Annual Meeting, 1986, pp. 1002-1006.

[18] D. Embrey, "Understanding human behaviour and error," Human Reliability Associates, vol. 1, pp. 1-10, 2005.

[19] P.-c. Li, G.-h. Chen, L.-c. Dai, and Z. Li, "Fuzzy logic-based approach for identifying the risk importance of human error," Safety science, vol. 48, pp. 902-913, 2010.

[20] E. Di Bella, A. Sillitti, and G. Succi, "A multivariate classification of open source developers," Information Sciences, vol. 221, pp. 72-83, 2013.

[21] P. Lenberg, R. Feldt, and L. G. Wallgren, "Behavioral software engineering: A definition and systematic literature review," Journal of Systems and Software, vol. 107, pp. 15-37, 2015.

[22] D. A. Norman, "Categorization of action slips," Psychological review, vol. 88, p. 1, 1981.

[23] M. E. R. F. Lopes and C. H. Q. Forster, "Application of human error theories for the process improvement of requirements engineering," Information Sciences, vol. 250, pp. 142-161, 2013.

[24] R. G. Mays, C. L. Jones, G. J. Holloway, and D. P. Studinski, "Experiences with defect prevention," IBM Systems Journal, vol. 29, pp. 4-32, 1990

[25] D. Würfel, R. Lutz, and S. Diehl, "Grounded requirements engineering: An approach to use case driven requirements engineering," Journal of Systems and Software, vol. 117, pp. 645-657, 2016. 
[26] Endres and H. D. Rombach, A handbook of software and systems engineering: Empirical observations, laws, and theories: Pearson Education, 2003.

[27] S. W. Dekker, "Illusions of explanation: A critical essay on error classification," The International Journal of Aviation Psychology, vol. 13, pp. 95-106, 2003.

[28] S. Lauesen and O. Vinter, "Preventing requirement defects: An experiment in process improvement," Requirements Engineering, vol. 6, pp. 37-50, 2001.

[29] Marnewick, J.-H. Pretorius, and L. Pretorius, "A perspective on human factors contributing to quality requirements: A cross-case analysis," in IEEE Industrial Engineering and Engineering Management, Singapore, 2011, pp. 389-393.

[30] K. M. de Oliveira, F. Zlot, A. R. Rocha, G. H. Travassos, C. Galotta, and C. S. de Menezes, "Domain-oriented software development environment," Journal of Systems and Software, vol. 72, pp. 145-161, 2004.

[31] S. Viller, J. Bowers, and T. Rodden, "Human factors in requirements engineering:: A survey of human sciences literature relevant to the improvement of dependable systems development processes," Interacting with Computers, vol. 11, pp. 665-698, 1999.

[32] M. A. Teruel, E. Navarro, V. López-Jaquero, F. Montero, and P. González, "An empirical evaluation of requirement engineering techniques for collaborative systems," in Evaluation \& Assessment in Software Engineering (EASE 2011), 15th Annual Conference on, 2011, pp. 114-123.

[33] E. Bjarnason, P. Runeson, M. Borg, M. Unterkalmsteiner, E. Engström, B. Regnell, et al., "Challenges and practices in aligning requirements with verification and validation: a case study of six companies," Empirical Software Engineering, vol. 19, pp. 1809-1855, 2014.

[34] J. E. Hannay, E. Arisholm, H. Engvik, and D. I. Sjøberg, "Effects of personality on pair programming," Software Engineering, IEEE Transactions on, vol. 36, pp. 61-80, 2010.

[35] P. Holtkamp, J. P. Jokinen, and J. M. Pawlowski, "Soft competency requirements in requirements engineering, software design, implementation, and testing," Journal of Systems and Software, vol. 101, pp. 136-146, 2015.

[36] S. Ferreira, J. Collofello, D. Shunk, and G. Mackulak, "Understanding the effects of requirements volatility in software engineering by using analytical modeling and software process simulation," Journal of Systems and Software, vol. 82, pp. 1568-1577, 2009.

[37] R. Govindaraju, A. Bramagara, L. Gondodiwiryo, and T. Simatupang, "Requirement Volatility, Standardization and Knowledge Integration in Software Projects: An Empirical Analysis on Outsourced IS Development Projects," Journal of ICT Research and Applications, vol. 9, pp. 68-87, 2015.

[38] M. Davis, N. Otero, K. Dautenhahn, C. L. Nehaniv, and S. D. Powell, "Creating a software to promote understanding about narrative in children with autism: Reflecting on the design of feedback and opportunities to reason," in 2007 IEEE 6th International Conference on Development and Learning, 2007, pp. 64-69.

[39] T. Javed and Q. S. Durrani, "A study to investigate the impact of requirements instability on software defects," ACM SIGSOFT Software Engineering Notes, vol. 29, pp. 1-7, 2004.

[40] P. Mohagheghi and R. Conradi, "An empirical study of software change: origin, acceptance rate, and functionality vs. quality attributes," in Empirical Software Engineering, 2004. ISESE'04. Proceedings. 2004 International Symposium on, 2004, pp. 7-16.

[41] D. Crowther and G. Lancaster, Research methods: Routledge, 2012.

[42] M. Bano, S. Imtiaz, N. Ikram, M. Niazi, and M. Usman, "Causes of requirement change-a systematic literature review," in Evaluation \& Assessment in Software Engineering (EASE 2012), 16th International Conference on, 2012, pp. 22-31.

[43] F. Gravetter and L.-A. Forzano, Research methods for the behavioral sciences: Cengage Learning, 2011.

[44] H. a. Schaubroeck, "Confirmatory modelling in organizational behaviour/human resource management: issues and applications," Journal of Management, 1990.

[45] K. A. Markus, "Principles and Practice of Structural Equation Modeling by Rex B. Kline," Structural Equation Modeling: A Multidisciplinary Journal, vol. 19, pp. 509-512, 2012.

[46] R. B. Kline, Principles and practice of structural equation modeling: Guilford publications, 2015.

[47] J. F. Hair, W. C. Black, B. J. Babin, R. E. Anderson, and R. L. Tatham, Multivariate data analysis vol. 6: Pearson Prentice Hall Upper Saddle River, NJ, 2006.

[48] P. J. Swerdzewski, Should we worry about the way we measure worry over time? A longitudinal analysis of student worry during the first two years of college: ProQuest, 2008.

[49] D. Harrington, Confirmatory factor analysis: Oxford University Press, USA, 2008.

[50] M. Byrne, Structural equation modeling with AMOS: Basic concepts, applications, and programming: Routledge, 2013.

[51] Hooper, J. Coughlan, and M. Mullen, "Structural equation modelling: Guidelines for determining model fit," Articles, p. 2, 2008.

[52] J. Jaccard and C. K. Wan, LISREL approaches to interaction effects in multiple regression: Sage, 1996.

[53] V. Kachitvichyanukul, K. Sethanan, and P. Golinska-Dawson, Toward Sustainable Operations of Supply Chain and Logistics Systems: Springer, 2015.

[54] J. Ko and B. A. Myers, "A framework and methodology for studying the causes of software errors in programming systems," Journal of Visual Languages \& Computing, vol. 16, pp. 41-84, 2005.

TABLE XII. TOTAL NUMBER OF FACtORS AND VARIANCE EXTRACTED

\begin{tabular}{|c|c|c|c|c|c|c|c|c|c|}
\hline \multirow[b]{2}{*}{ 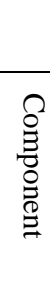 } & \multicolumn{3}{|c|}{ Initial Eigenvalues } & \multicolumn{3}{|c|}{ Extraction Sums of Squared Loadings } & \multicolumn{3}{|c|}{ Rotation Sums of Squared Loadings } \\
\hline & $\stackrel{\vec{O}}{\vec{D}}$ & 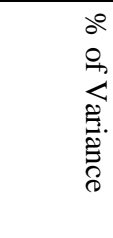 & 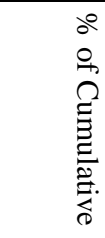 & $\begin{array}{l}\overrightarrow{0} \\
\stackrel{0}{\tilde{D}}\end{array}$ & 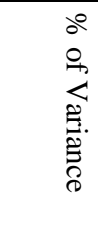 & 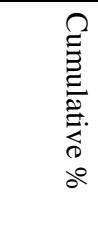 & $\begin{array}{l}\overrightarrow{0} \\
\stackrel{0}{\tilde{D}}\end{array}$ & 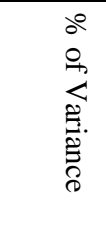 & 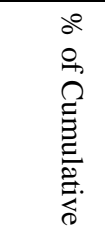 \\
\hline 1 & 34.098 & 34.098 & 34.098 & 34.098 & 25.817 & 25.817 & 4.648 & 25.821 & 25.821 \\
\hline 2 & 21.311 & 55.410 & 21.311 & 55.410 & 23.171 & 48.988 & 4.190 & 23.28 & 49.101 \\
\hline 3 & 5.379 & 5.379 & 60.789 & 11.801 & 60.789 & 5.379 & 2.144 & 11.909 & 61.01 \\
\hline
\end{tabular}


TABLE XIII. GOODNESS OF FIT STATISTICS OF CFA ModEL

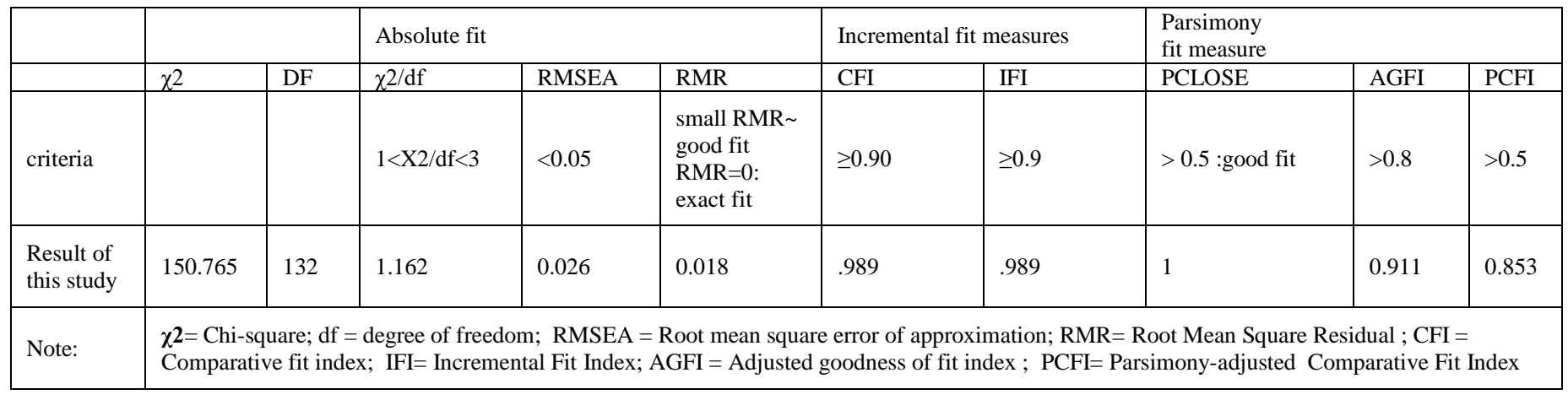

